Revue des patrimoines

$40 \mid 2019$

Lits historiques. Première anthologie des lits européens du XVe au XIXe siècle

\title{
Le lit provenant du château d'Effiat (Puy-de-Dôme) conservé au musée du Louvre
}

The Bed from the Effiat Chateau (Puy-de-Dôme) held by the Louvre

\section{Agnès Bos}

\section{(2) OpenEdition}

\section{Journals}

Édition électronique

URL : http://journals.openedition.org/insitu/23212

DOI : 10.4000/insitu.23212

ISSN : 1630-7305

Éditeur

Ministère de la Culture

Référence électronique

Agnès Bos, "Le lit provenant du château d'Effiat (Puy-de-Dôme) conservé au musée du Louvre », In Situ [En ligne], 40 | 2019, mis en ligne le 15 septembre 2019, consulté le 14 novembre 2019. URL : http://journals.openedition.org/insitu/23212 ; DOI : 10.4000/insitu.23212

Ce document a été généré automatiquement le 14 novembre 2019.

\section{cc) (†)}

In Situ Revues des patrimoines est mis à disposition selon les termes de la licence Creative Commons Attribution - Pas d'Utilisation Commerciale - Pas de Modification 4.0 International. 


\title{
Le lit provenant du château d'Effiat (Puy-de-Dôme) conservé au musée du Louvre
}

The Bed from the Effiat Chateau (Puy-de-Dôme) held by the Louvre

\author{
Agnès Bos
}

Je tiens à remercier Hubert de Moroges, propriétaire du château d'Effiat, de m'avoir si aimablement accueillie à Effiat et de m'avoir laissé consulter les archives du château, ainsi qu'Olivier Paradis pour son amical accompagnement dans ces recherches. Mes remerciements s'adressent également à Alice Motte, aux archives départementales du Puy-de-Dôme, à JeanChristophe Ton-That, Christine Chabod, Nicolas Courtin, Anne-Myrtille Renoux et Marguerite Momesso.

En mémoire d'Alain Gibert

1 «Lit d'honneur où aurait couché Richelieu $»^{1}$ selon le Dr Balme, érudit auvergnat, le lit provenant du château d'Effiat (Puy-de-Dôme) et présenté aujourd'hui dans les salles du département des Objets d'art du musée du Louvre ${ }^{2}$ (fig. 1) n'échappe pas à cette tenace habitude d'associer un lit historique à un personnage de premier plan, comme si la présence d'un occupant nocturne illustre était nécessaire pour apprécier l'importance d'un meuble. Pourtant, ce lit n'a pas besoin de cette légende pour mériter une étude approfondie qui n'avait jusqu'ici jamais été menée, en dépit d'une bibliographie abondante, mais superficielle. Son format, la richesse des textiles qui le composent, sa provenance documentée qui le lie à l'une des plus importantes familles du règne de Louis XIII, la rareté d'une telle pièce, ou encore son destin après le XVII ${ }^{e}$ siècle, sont autant de raisons qui suffisent à s'étonner qu'une étude détaillée n'ait pas été conduite plus tôt. Ainsi, bien que souvent présenté comme l'un des rares exemples encore existant des premiers lits "à la française ", il a été daté, selon les auteurs, entre le premier tiers du XVII ${ }^{e}$ siècle et les années $1675^{3}$. Souvent, il est présenté comme le lit du maréchal d'Effiat, mort en 1632, tout en étant daté des années 1660 ou $1670 \ldots$ Nous proposons donc ici de dresser ce que les archives et la documentation nous livrent comme informations sur ce lit et les hypothèses qui peuvent en être tirées, mais aussi 
de retracer le parcours du meuble depuis le château d'Effiat, et d'en présenter une première critique matérielle.

Figure 1

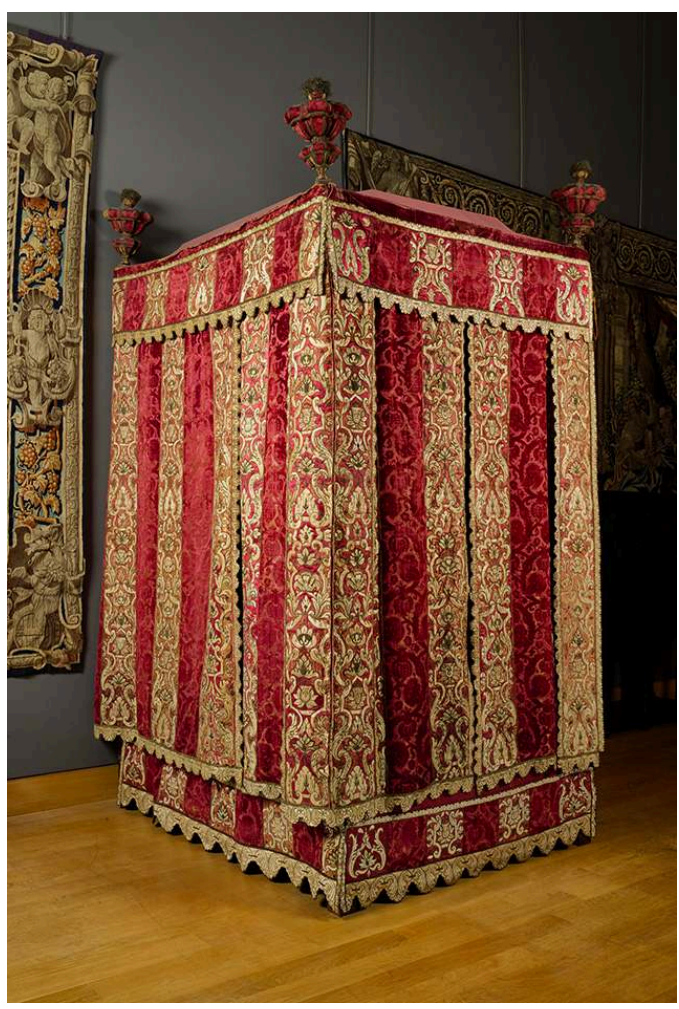

Lit provenant du château d'Effiat. Musée du Louvre, département des Objets d'art, dépôt du musée de Cluny (inv. Cl. 25550).

Phot. Stéphane Maréchalle. (c) RMN - Grand Palais (Musée du Louvre).

\section{Une provenance : Effiat}

2 Commençons par une certitude : contrairement à d'autres objets à qui l'on assigne une provenance imaginaire ou invérifiable, le lit provient bel et bien du château d'Effiat, situé au nord-est d'Aigueperse. Il est possible de retracer son historique sans hésitation. Le lit est décrit dans un guide touristique en 1849 alors qu'il se trouvait encore dans le château :

[...] dans la chambre à coucher du maréchal d'Effiat, dont l'état de religieuse conservation vous reporte invinciblement à deux siècles en arrière [...] ce qui frappe tout d'abord le regard, c'est le grand lit carrée (sic) de l'ancien gouverneur, dont les riches tentures en velours et soie cramoisis, brodés or et argent, sont soutenues par quatre colonnes surmontées de bouquets de plumes, comme un dais ${ }^{4}$.

Quelques années plus tard, le propriétaire d'alors, Jean Boucard, après avoir commencé à détruire partiellement le château, entreprit d'en vendre le mobilier ${ }^{5}$. Lors de la séance du 19 avril 1856, le président de la Société d'émulation du département de l'Allier informait ses membres de la vente prochaine du «mobilier historique et princier du château d'Effiat » et notamment d'un "grand lit à baldaquin, dont les rideaux, les lambrequins et le piqué de la couche sont en brocard, retenus aux angles des piliers par quatre larges embrasses en galon de vermeil $»^{6}$. Par un canal que nous ignorons, 
Edmond Du Sommerard (1817-1885), directeur du musée de Cluny, eut connaissance de la vente à venir et en avertit son ministre, dans la semaine qui précédait la mise aux enchères, proposant de se rendre à Effiat pour juger de l'intérêt d'acquérir certaines des pièces ainsi offertes. On ne peut qu'admirer la réactivité dont fit alors preuve l'administration : le samedi suivant, Du Sommerard était à Effiat et envoyait un rapport circonstancié avec une liste des objets qu'il souhaitait acquérir pour son musée et ceux qui pourraient rejoindre le garde-meuble de la Couronne ${ }^{7}$. D'après un témoignage plus tardif, il était accompagné par le comte Émilien de Nieuwerkerke, directeur général des Musées et allié à la famille Sampigny qui était le précédent propriétaire du château d'Effiat ${ }^{8}$. Du Sommerard reçut l'autorisation d'acheter les lots qui avaient retenu son attention, sous réserve d'un prix raisonnable. Au total, lors de la vente qui se tint le lundi, il fut en mesure d'acquérir pour le compte de l'État un nombre considérable d'objets :

Pour le musée de Cluny :

5 - Le mobilier dit de la chambre du maréchal: lit à baldaquin et six fauteuils (inv. Cl. 2550 à 2556), 1146 fr.

6 - Un lit à baldaquin de damas rouge et environ 160 mètres de damas (Cl. 2558 et 2559), 1997,50 fr.

7 - Une plaque de cheminée aux armes du maréchal d'Effiat (Cl. 2562), 135,50fr.

8 - Un paravent en velours et soie brodés (Cl. 2557), 100 fr.

9 - Un lit à baldaquin de damas vert et un lot de même tissu (Cl. 2560 et 2561), $176 \mathrm{fr}$.

10 - Pour le garde-meuble de la Couronne:

11 - Neuf fauteuils et un canapé couverts de damas vert, $1676 \mathrm{fr}$.

12 - Douze fauteuils et un canapé en bois peint sculpté, couverts de tapisserie de Beauvais, « sujets de Boucher et fables de La Fontaine » (GMT 1168/1 à 13), 2636 fr.

13 - Cinq pièces de tapisseries de Beauvais à fond blanc, décor de fleurs, paniers et potiches, $2309 \mathrm{fr}$.

14 - Dix fauteuils, un canapé et un tabouret en bois doré couvert de damas rouge, $1767 \mathrm{fr}$.

15 On notera que la tapisserie du $\mathrm{xv}^{\mathrm{e}}$ siècle dont Edmond Du Sommerard jugeait qu'elle "conviendrait parfaitement à l'hôtel de Cluny" n'a finalement pas été achetée, probablement du fait d'une enchère trop élevée ${ }^{9}$.

16 Tous les objets ainsi acquis par l'État ont connu des destins différents. Le lit dit du maréchal fut exposé pendant une longue période dans la salle 22 du musée de Cluny, dite chambre de la Reine blanche ${ }^{10}$. À la veille de la Seconde Guerre mondiale, il fut décidé de déposer au château d'Azay-le-Rideau (Indre-et-Loire) les trois lits provenant du château d'Effiat ainsi que les six fauteuils. Pour une raison que nous ignorons, le lit dit du maréchal et les fauteuils ne suivirent jamais les deux autres couches vers les bords de l'Indre. Un document conservé dans les archives du musée de Cluny, non daté mais postérieur à 1948, précise : «Ces objets n'ont jamais été transportés à Azay. Les fauteuils pris en charge par le Mobilier national le 22 septembre 1939 ont été prêtés pendant la guerre à la Comédie-Française d'où ils ont fait retour au Louvre en 1948. Le lit, pris en charge par le Mobilier national, a fait retour au Louvre où il est exposé dans les salles de la Colonnade ». Des photographies témoignent de son emplacement, d'ailleurs assez peu convaincant du fait de ses proportions, dans l'alcôve de la chambre de la Colonnade (fig. 2) où était précédemment placé un autre lit, italien, provenant de la collection 
Piot $^{11}$. Depuis le réaménagement des salles du département des Objets d'art ouvertes en 1993, le lit est présenté avec les fauteuils et d'autres meubles, tapisseries et objets dans une vaste salle qui porte le nom d'Effiat.

Figure 2

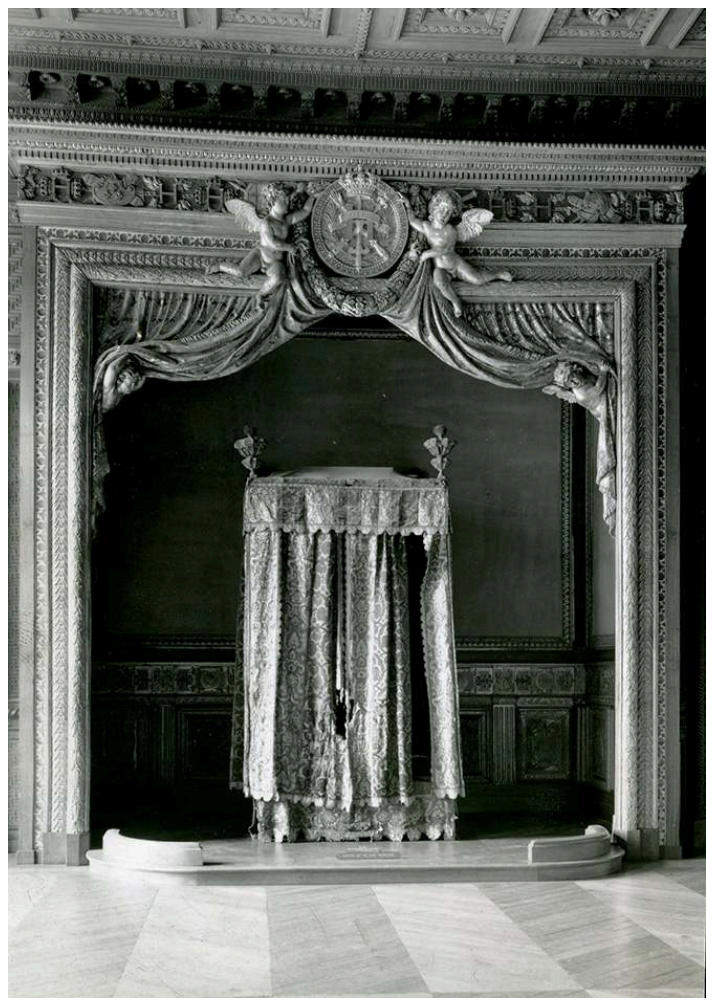

Le lit provenant d'Effiat dans l'alcôve de la chambre de la Colonnade au musée du Louvre, 1958.

(c) Documentation du département des Objets d'art.

\section{Le château d'Effiat du vivant du maréchal d'Effiat}

Revenons maintenant au château d'Effiat pour tenter de cerner à quelle époque le lit a été réalisé et donc qui fut son commanditaire. Le guide de 1849 cité plus haut désigne la pièce dans laquelle se trouvaient le lit et les six fauteuils assortis comme la chambre du maréchal d'Effiat, et cette dénomination est celle adoptée dans d'autres descriptions contemporaines, reprise par la suite, comme on l'a vu, par Edmond Du Sommerard et les autres historiens et conservateurs qui lui succédèrent. Il paraissait certainement naturel qu'une chambre aussi pieusement conservée dans son état d'origine du XVII ${ }^{\mathrm{e}}$ siècle, ou supposé tel, ne pût qu'être celle du plus puissant et prestigieux membre de la famille, par ailleurs (re)constructeur du château: Antoine Ruzé d'Effiat (v. 1581-1632). Né Antoine Coëffier, d'un père désargenté, il bénéficia de la protection de son riche grand-oncle maternel, Martin Ruzé, dont il prit le nom et les armes avant d'en hériter la fortune en 1613, l'aidant ainsi dans sa fulgurante ascension sociale et politique. Dès 1610, son mariage avec Marie de Fourcy, fille de l'intendant des Bâtiments du roi, avait constitué une première marche dans cette ascension. D'abord au service de l'armée royale, il se voit notamment confier une mission comme ambassadeur extraordinaire en Grande-Bretagne en 1624-1625 pour négocier le mariage d'Henriette de France, sœur 
de Louis XIII, avec le futur roi d'Angleterre Charles I ${ }^{\text {er }}$. Entré au conseil du roi en 1624, il devint surintendant des finances en 1626, reçut le titre de marquis en 1627 et fut fait maréchal en 1631. Sa mort soudaine en 1632, lors d'une campagne militaire en Allemagne, interrompit cette brillante carrière favorisée par la protection du cardinal de Richelieu ${ }^{12}$.

À la tête d'une fortune devenue considérable, Antoine Ruzé d'Effiat s'était lancé au milieu des années 1620 dans plusieurs chantiers architecturaux ambitieux. Outre un hôtel dans le quartier de Saint-Germain-l'Auxerrois, rue Saint-Thomas du Louvre ${ }^{13}$, il entreprit de faire remanier et agrandir le château de Chilly (aujourd'hui ChillyMazarin, Essonne) dont il avait hérité en même temps que la seigneurie de chilly et Longjumeau de son grand-oncle, et le château d'Effiat qui lui venait de sa famille paternelle. Pour les deux, il fit très certainement appel au même architecte, Clément II Métezeau $^{14}$, architecte des Bâtiments du roi depuis 1615, avant de le remplacer, sur les deux chantiers, par Jacques Lemercier au cours de l'année $1630^{15}$. À Effiat, l'édifice précédent, probablement rebâti par le père d'Antoine après son acquisition du domaine d'Effiat en 1557, a dû servir de base aux nouveaux aménagements et agrandissements entrepris à cette époque, notamment avec l'ajout de deux ailes au corps de bâtiment principal. Si la mort soudaine du maréchal a pu ralentir les travaux alors en cours, ils ne furent néanmoins pas totalement abandonnés et se poursuivirent jusqu'en $1635^{16}$, mais le château devait rester inachevé (fig. 3). Les destructions opérées après 1855 ne permettent pas de connaître l'aménagement intérieur originel du château et les sources iconographiques sont quasi inexistantes; seule une étude minutieuse des différentes sources manuscrites subsistantes (inventaires après décès, procès-verbaux de visites de l'époque révolutionnaire) confrontés aux parties encore en place et aux sources concernant le chantier, exploitées par Céline Beaufrère dans son mémoire de maîtrise, permettraient d'en dresser un état plus précis.

Figure 3

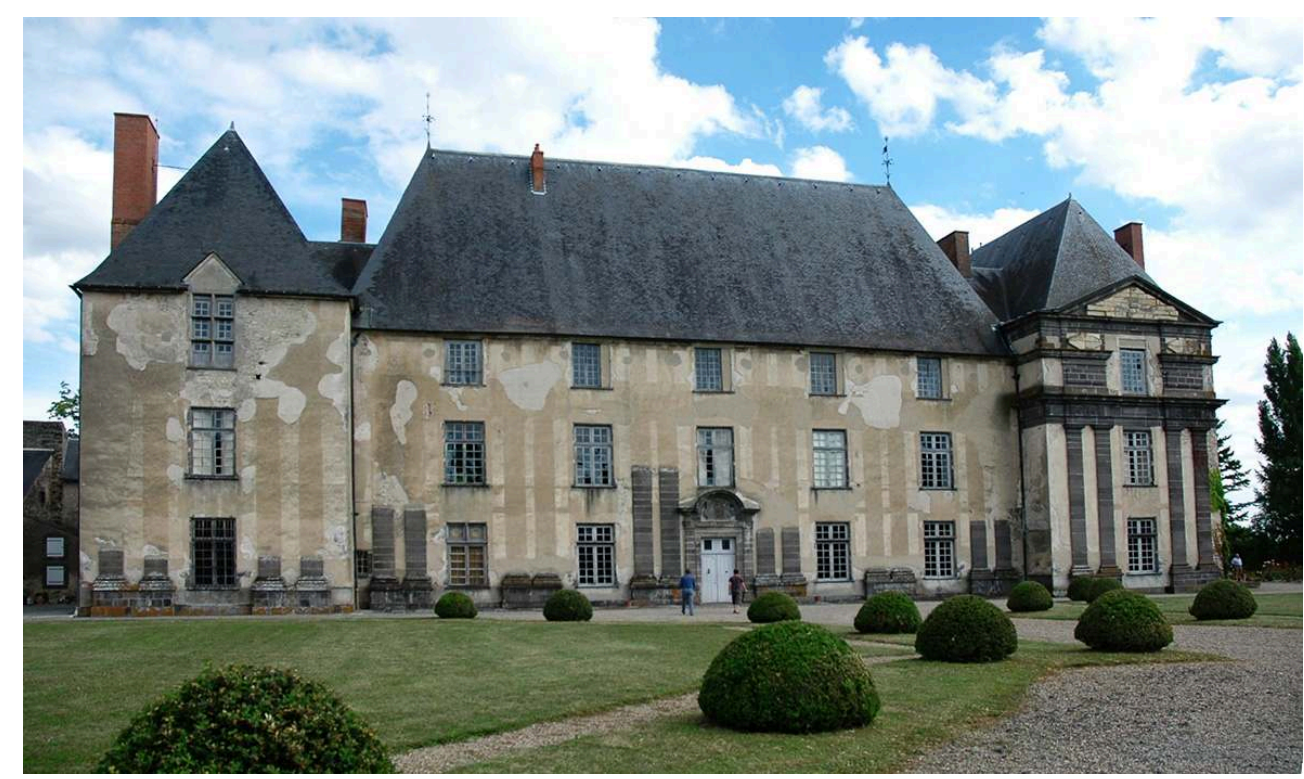

Le château d'Effiat, façade sur jardin.

(c) Jastrow, 2006. 
Il est néanmoins possible de savoir qu'à la mort du maréchal, en 1632, l'essentiel des meubles qu'il possédait se trouvait dans son hôtel parisien et dans son château à Chilly ${ }^{17}$. De nombreux lits sont alors recensés. Parmi les plus hautement prisés se trouve une pièce ainsi décrite: "Ung lit de velours rouge cramoisy en dix pantes et trois soubassemens, trois rideaux, quatre quantonnières de velours rouge cramoisy, la couverture de parade, le fonds de [?] et dessus de satin, lesd. rideaux doublez de satin de mesme couleur garnis de bouttons à grosse ollives à queue et lacs d'amour de crespine d'or et d'argent ». Peut-il s'agir du lit aujourd'hui conservé au Louvre ? Nous en doutons car certains détails comme les lacs d'amour ne correspondent pas; par ailleurs, la description ne mentionne pas une garniture par bandes, ni de pommes au sommet du lit, alors que ces éléments sont indiqués à plusieurs reprises sur d'autres lits apparaissant dans ce même inventaire ${ }^{18}$.

Le fait que le château d'Effiat fût alors peu meublé peut s'expliquer par les travaux en cours. On notera cependant qu'en septembre 1629, le cardinal de Richelieu et l'étatmajor de l'armée, remontant du Languedoc vers Paris, s'arrêtèrent à Effiat. Selon le récit du maréchal de Bassompierre, le 4 septembre, «nous passâmes à Montferrant, \& fûmes dîner à Riom [...] puis coucher à Effiat, où nous demeurâmes jusques au $8^{\mathrm{e}} \mathrm{du}$ mois, à passer le tems. On y dansa un ballet, \& se firent de continuels festins ${ }^{19}$. Ces propos suggèrent un château habitable et meublé : y avait-on transporté spécialement des meubles pour cette occasion? Une autre hypothèse serait que le cardinal et sa suite aient logé non pas à Effiat même, mais dans le château tout voisin de Denone, dont le marquis d'Effiat avait fait l'acquisition peu de temps auparavant ${ }^{20}$.

\section{Martin Ruzé, marquis d'Effiat, commanditaire du lit ?}

21 À sa mort en 1632, le maréchal laissait cinq enfants vivants (une fille était décédée en bas âge), trois fils dont deux mineurs et deux filles, qui purent bénéficier de la protection et de la bienveillance du cardinal de Richelieu. Des trois fils, deux ont eu une vie qui les a mis souvent au premier plan des chroniques de l'époque : Jean, né en 1622, devenu plus tard abbé commendataire du Mont-Saint-Michel puis de Saint-Sernin de Toulouse, religieux mondain, et surtout le cadet, Henri, né en 1620, qui n'est autre que le marquis de Cinq-Mars, grand écuyer du roi à vingt ans, dont la conspiration contre Richelieu conduisit à son exécution en 1642. Au milieu de tous ces tumultes, le fils aîné du maréchal, Martin, né en 1612, est passé au second plan de l'histoire familiale, négligé par les historiens et parfois considéré comme intellectuellement faible, voire mentalement instable ${ }^{21}$. Il n'est pas dans le périmètre de cette étude d'écrire sa biographie, mais on notera que dans les mois qui précédèrent sa mort, le maréchal avait donné à son fils aîné le marquisat d'Effiat, en même temps qu'il l'émancipait ${ }^{22}$. Sur les traces de son père, mais certes manifestement sans son panache, Martin avait suivi la carrière des armes. Avec le soutien de Richelieu, il obtint en 1638 le gouvernement $\mathrm{du}$ Bourbonnais et de l'Auvergne, à l'époque où il se mariait, toujours grâce à l'entremise du cardinal, avec Isabelle d'Escoubleau de Sourdis ${ }^{23}$. Il semble résider, à partir de cette date, le plus souvent à Effiat, tandis que sa mère paraît avoir principalement habité, une fois veuve, dans son hôtel parisien nouvellement acquis ou au château de Chilly. N'oublions pas que Martin avait hérité d'une partie de la fortune colossale de son père et qu'il avait donc des moyens d'action. Il a d'ailleurs continué un 
peu les travaux entrepris par son père et avait des projets de nouveaux aménagements autour de $1638^{24}$.

La mort précoce de Martin, en 1644, explique certainement le peu de traces qu'il a laissées. Sa veuve mourut dix ans plus tard. Il n'a pas été possible de retrouver l'inventaire après décès de Martin Ruzé d'Effiat ${ }^{25}$. En revanche, l'inventaire de sa veuve est conservé dans le fonds des archives du château et il contient une collation de l'inventaire après décès de Martin. Il témoigne de la richesse de l'ameublement et du décor de la demeure à cette date et mériterait d'ailleurs une étude approfondie ${ }^{26}$. Pour ce qui concerne notre sujet, les rédacteurs de l'inventaire ont décrit dans « la chambre ou led. deffunct seigneur marquis d'Effiat est deceddé » :

ung bois \& couchette de lit garny de velours amarante couvert de passemant d'or à double tanture, la courte pointe et basse tante, le tout garny de frange, boutonnières aussy d'or à la rezerve de unze boutons dont trois à queue \& deux morceaux de passemant qui manquent à lad. garniture, ensemble les rideaux de damas et cantonnières (?), quatre pommes à ygrette, panaches bleus \& amarante avecq un tapis de table, deux fauteuils, une chaize à dossier, le tout de mesmes velours \& garniture, le tout estimé quinze centz livres $t$.

Par delà le fait que le lit ainsi désigné se trouve dans la chambre de Martin, c'est-à-dire dans la pièce même où le lit du Louvre se trouvait avant la vente de 1856, certains détails peuvent être mis en relation avec celui-ci. Le terme amarante, s'il peut surprendre car on trouve plus communément celui de cramoisi dans les inventaires de l'époque, désigne bien un rouge profond: le dictionnaire de Furetière précise qu'« on appelle aussi Amaranthe la teinture qui imite la couleur de [la] fleur [d'amaranthe]", c'est-à-dire "fort rouge $»^{27}$. Les "passemants d'or " peuvent correspondre aux filets métalliques présents sur le lit, et la « double tanture » à l'alternance des lés de velours avec des lés brodés. Plus problématique est la mention de boutons et de boutonnières, un type d'ornementation que l'on trouve bien sur les lits du XVII ${ }^{e}$ siècle $^{28}$, mais qui n'est pas visible sur le lit du Louvre. Par ailleurs, ce dernier possède un chantourné qui ne paraît pas pouvoir être antérieur au milieu du xvII siècle, mais son examen semble suggérer qu'il s'agit d'un remaniement postérieur ${ }^{29}$ (fig. 4). 
Figure 4

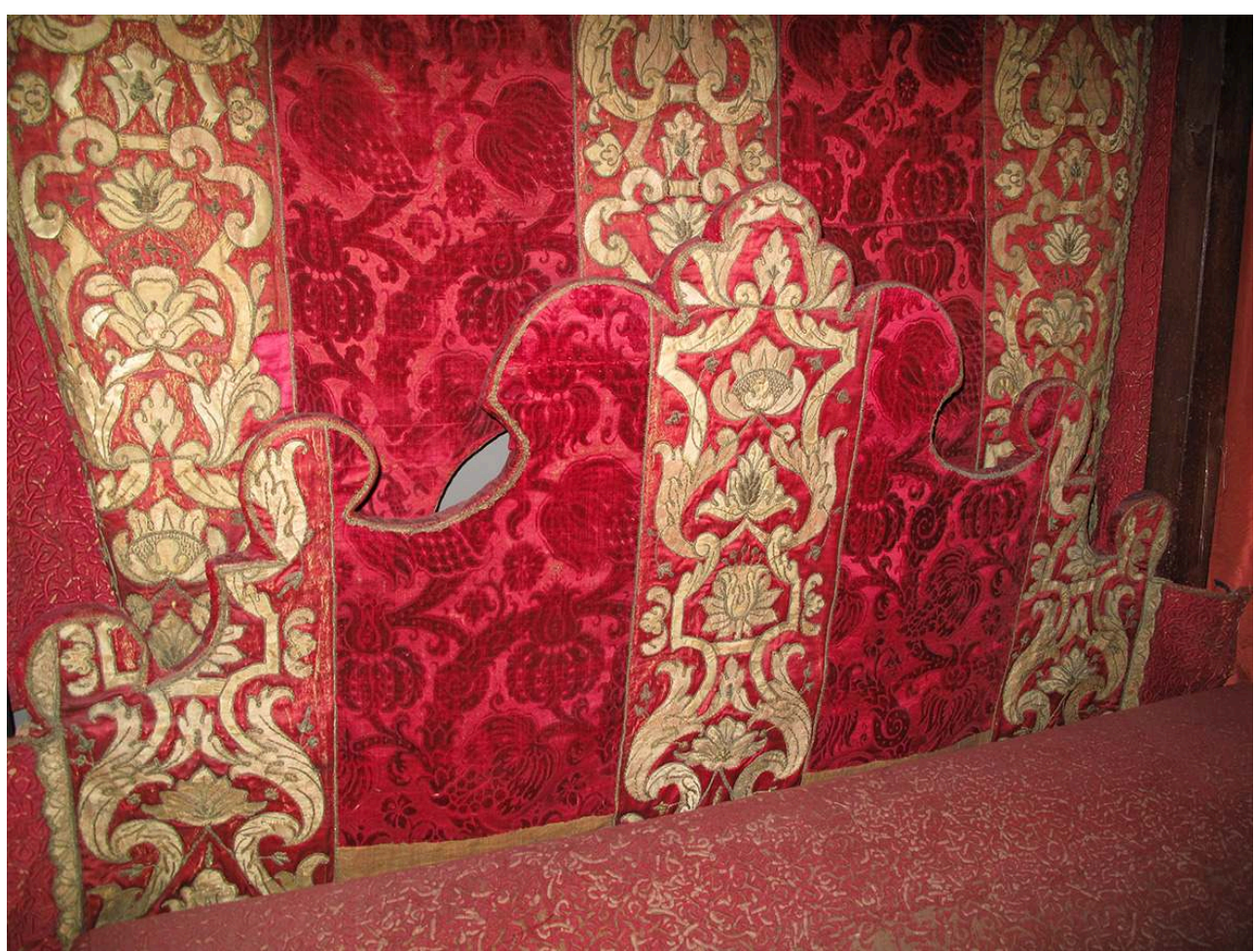

Lit provenant du château d'Effiat, vue du chantourné. Musée du Louvre, département des Objets d'art, dépôt du musée de Cluny.

(c) Anne Jacquin, 2009.

En outre, l'inventaire de 1654 ne mentionne que « deux fauteulx, une chaize à dossier, le tout de mesme velours \& garniture ", alors que six fauteuils galonnés semblablement, et avec une pièce en broderie d'application identique à celle du lit au centre de l'assise et du dossier (fig. 5) furent acquis avec le lit. Le format des fauteuils ne paraît, au demeurant, guère compatible avec une datation autour de 1630-1640: les hauts dossiers se répandent plus tardivement, après le milieu du siècle. Comme en témoignent par exemple les gravures d'Abraham Bosse, les fauteuils qui accompagnaient les lits de cette époque ont un dossier plus bas, de format oblong, et des bras d'accotoir droits et non courbes, souvent tournés. Le musée du Louvre en conserve ainsi deux exemplaires ${ }^{30}$. On peut se demander si les fauteuils d'Effiat conservés ne sont pas des réalisations postérieures au lit, en utilisant du velours et des broderies qui restaient ${ }^{31}$. 


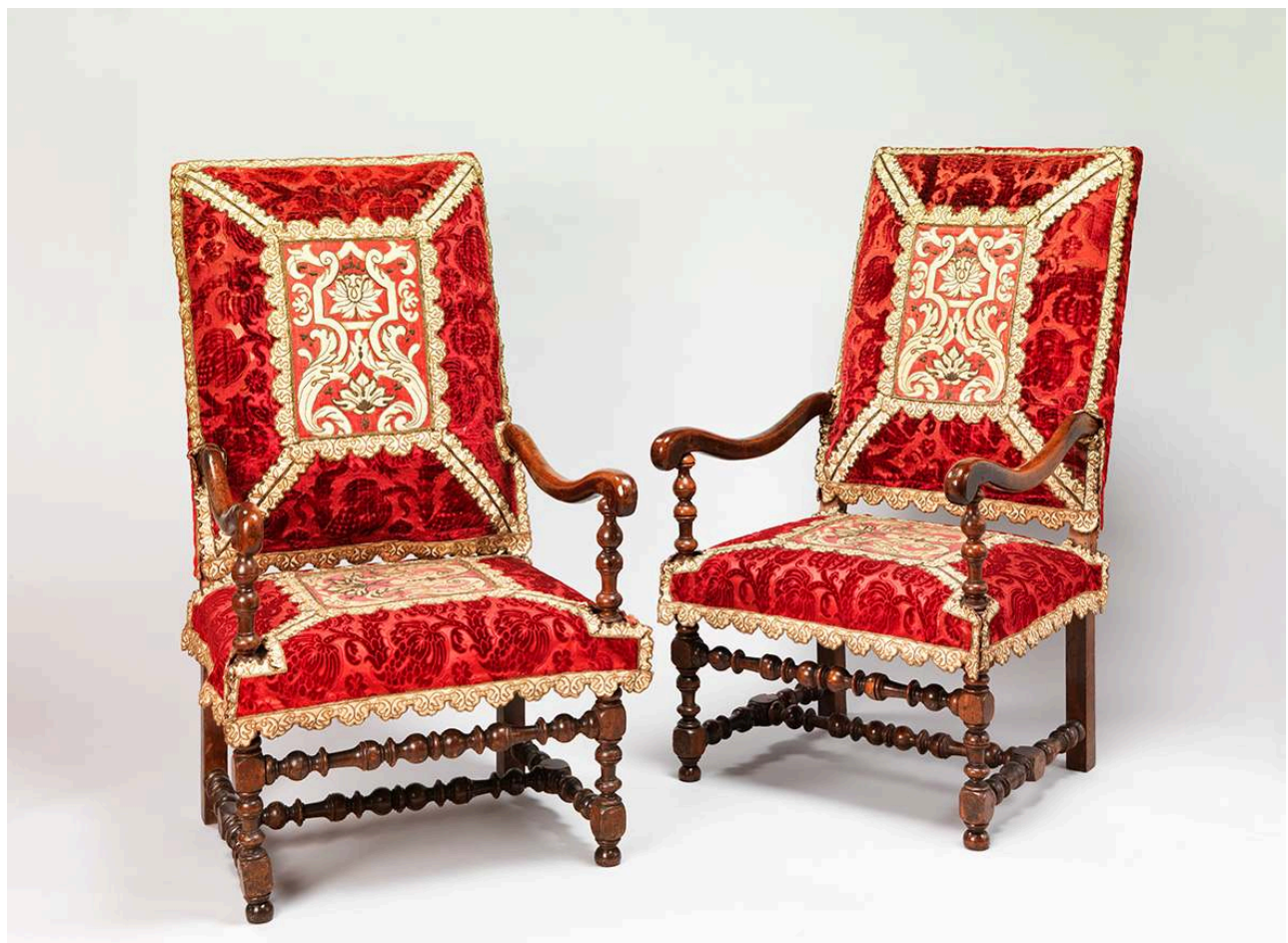

Deux fauteuils provenant du château d'Effiat. Musée du Louvre, département des Objets d'art, dépôt du musée de Cluny.

Phot. Philippe Fuzeau. @ Musée du Louvre, dist. RMN - Grand Palais.

Il n'est donc pas possible de clairement établir si le lit décrit dans la chambre du feu marquis d'Effiat en 1654 peut être identifié avec le lit aujourd'hui conservé au musée du Louvre. Il s'agit néanmois d'une hypothèse que l'on ne peut exclure, mais il faudrait poursuivre l'enquête en s'intéressant notamment au destin du château d'Effiat du vivant du fils de Martin, Antoine II Ruzé (1638-1719, mort sans descendance), et aux deux autres lits achetés par le musée de Cluny en même temps que le lit déposé depuis au Louvre, et qui sont manifestement plus tardifs.

\section{Un lit « à la française »}

Si cette hypothèse était confirmée, le lit d'Effiat serait bien un « lit Louis XIII », et donc l'un des plus anciens témoignages conservés de ce type de lits qui, selon les mots d'Edmond Bonnaffé, «n'est plus l'œuvre du menuisier ni du sculpteur: c'est le triomphe du tapissier, un monument d'étoffe, de broderie et de passementerie ${ }^{32}$. Il reprend le format cubique du lit à quatre colonnes avec un dais (ou baldaquin) de mêmes dimensions que la couche, caractéristique du lit dit «à la française »; il s'agit également d'un « lit de bout ", c'est-à-dire destiné à être placé perpendiculairement au mur, et il appartient au type des lits "à rideaux $»^{33}$. Ce sont un format et une disposition que l'on connait bien pour les retrouver notamment sur plusieurs gravures d'Abraham Bosse ${ }^{34}$, contemporaines du lit d'Effiat. Ce dernier décline cependant une version spécialement luxueuse du fait de l'alternance des lés de velours de soie ciselé à décor d'ananas avec des lés constitués d'un fond de satin de soie rouge orné de broderies d'application en satin de soie claire, brodés de filets métalliques, cannetilles 
et fil de soie jaune; des galons brodés de filets métalliques bordent chaque partie (fig. 6).

Figure 6

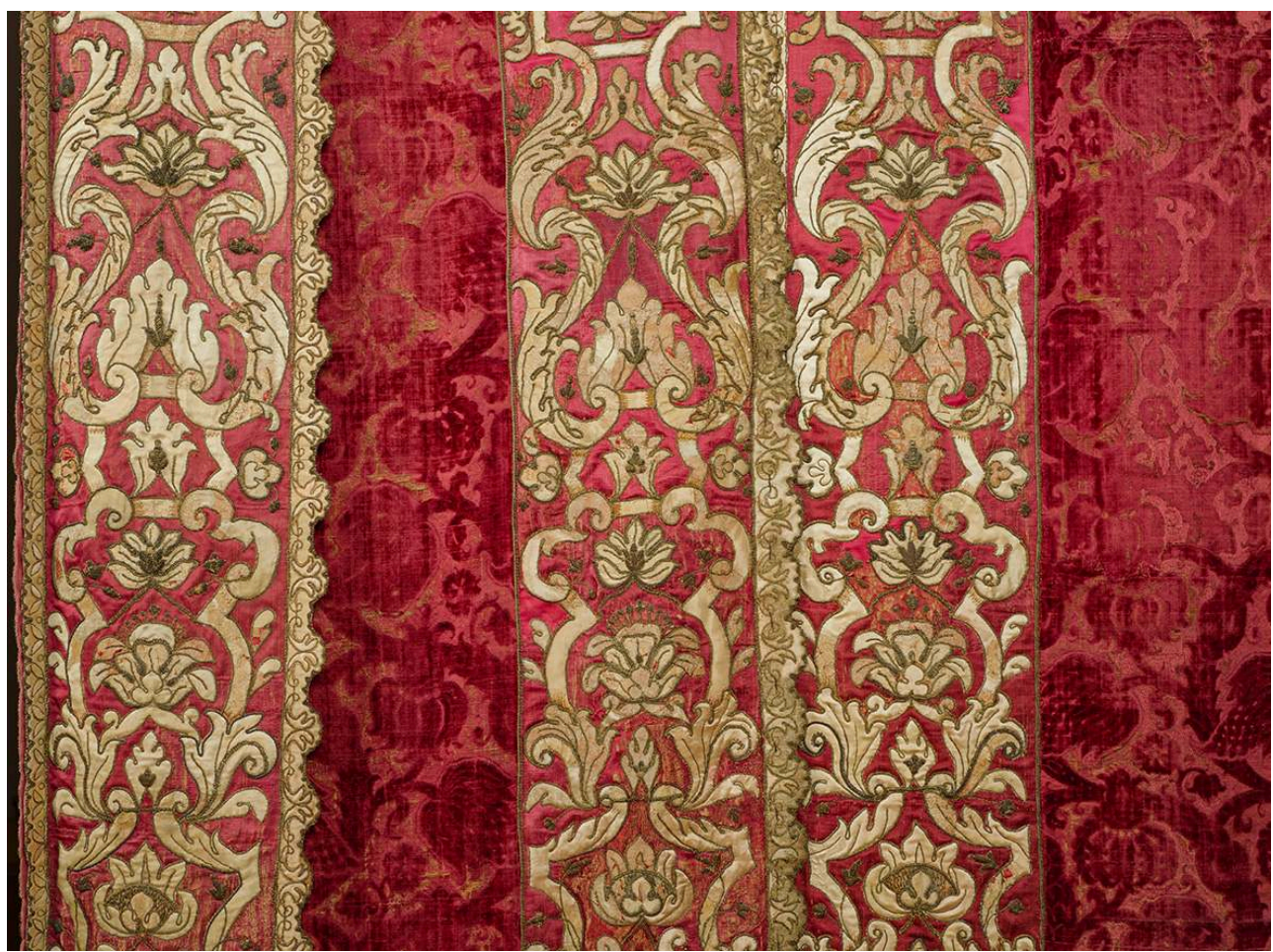

Lit provenant du château d'Effiat, détail des rideaux. Musée du Louvre, département des Objets d'art, dépôt du musée de Cluny.

Phot. Stéphane Maréchalle. (c) RMN - Grand Palais (Musée du Louvre).

Les broderies d'application, des candélabres déployant des motifs floraux encadrés par deux bordures prenant la forme de rubans ou de feuilles, s'inspirent des gravures d'ornements contemporaines mais peuvent aussi être rapprochées de gravures de parterres de jardin réalisées par André Le Nôtre, certaines reprenant des parterres dessinés par Nicolas Bouticourt, jardinier du roi au Palais-Royal ${ }^{35}$ (fig. 7). 
Figure 7

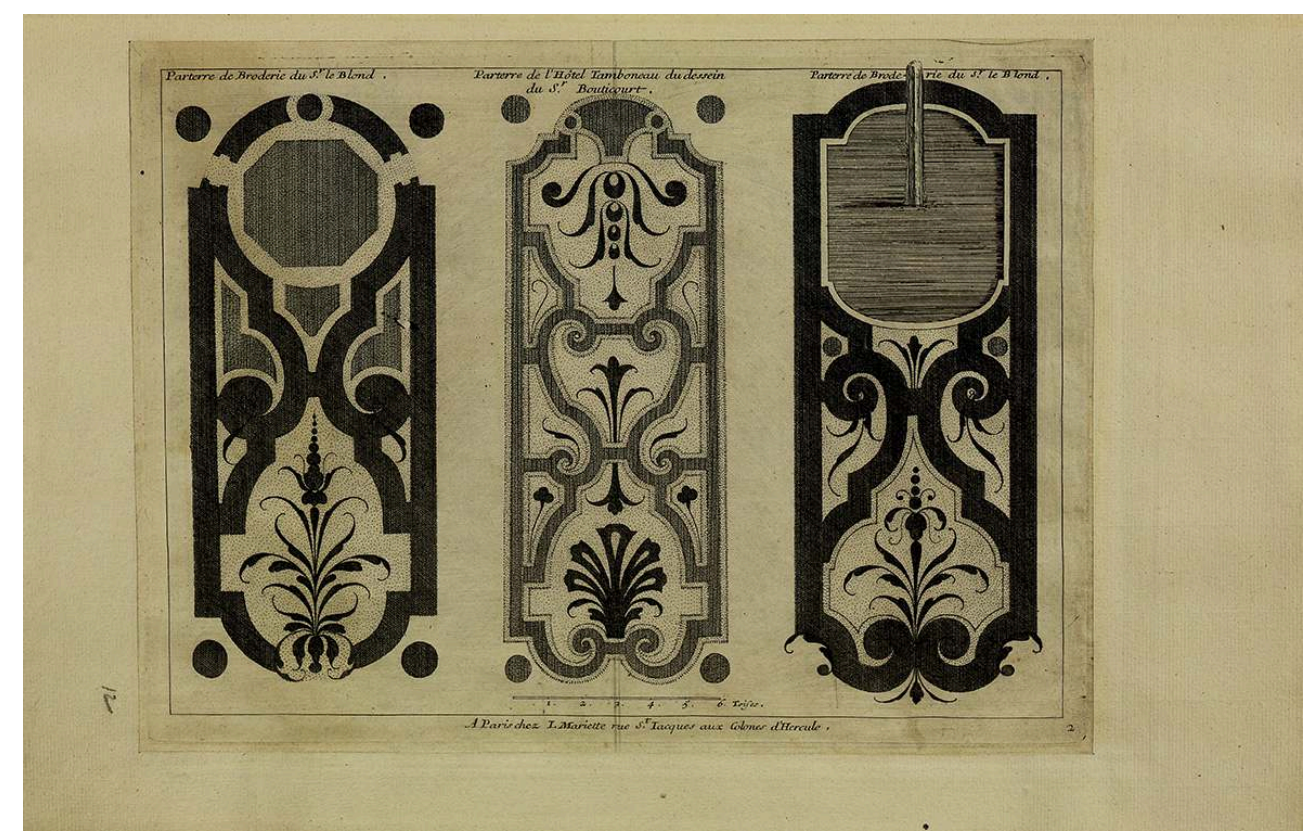

Gravures de divers parterres, Paris.

(c) Bibliothèque de l'Institut national d'histoire de l'art, collections Jacques Doucet, Fol Est 139.

Le principe de l'alternance velours/broderies d'application est repris sur l'ensemble du lit : les rideaux, les pentes, les soubassements, mais aussi sur le dossier. La courtepointe possède, elle, un décor brodé différent, un boutis couvert sur le dessus d'un tissu de soie rouge et sur l'envers d'un tissu de soie verte ${ }^{36}$, et le fond du ciel de lit est brodé, sur sa périphérie, d'un délicat décor de bouquets et de branchages (fig. 8). Le compartimentage de ce ciel de lit suggère que la forme en léger dôme qui se voit aujourd'hui correspond à la disposition d'origine. Par contraste, les parties en bois de noyer sont très simples, des montants de section carrée au niveau du chevet et des colonnes au niveau du pied. 
Figure 8

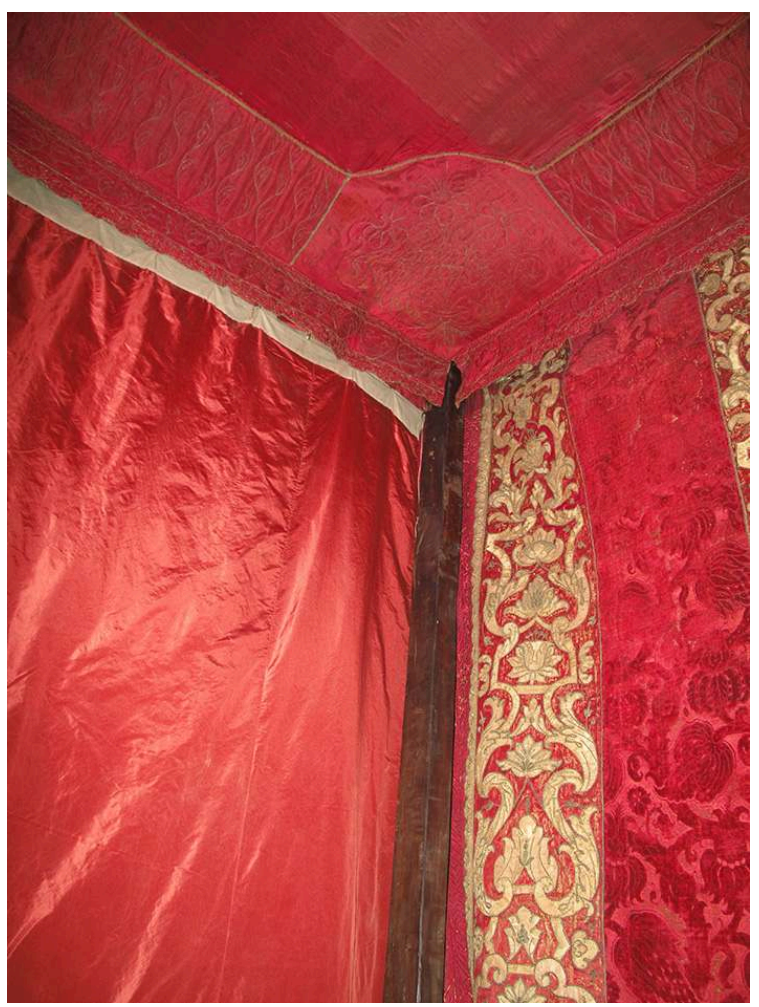

Lit provenant du château d'Effiat, vue partielle de l'intérieur. Musée du Louvre, département des Objets d'art.

(c) Anne Jacquin, 2009.

Il n'est malheureusement pas possible de savoir où ce lit a été réalisé. Peut-être a-t-il une origine parisienne: on sait que Martin, si c'est lui qui en fut le premier propriétaire, y a beaucoup demeuré avant de se marier et de s'établir à Effiat, et Paris était incontestablement une place où commander une telle pièce. Mais la richesse des parties textiles peut aussi suggérer une réalisation lyonnaise. Une analyse approfondie de l'inventaire après décès de 1654 permettrait peut-être de comprendre quels furent les circuits de commande du fils du maréchal d'Effiat.

\section{Critique d'authenticité}

Lors de leur acquisition en 1856, Edmond Du Sommerard avait signalé l'état de conservation médiocre " [du] lit et [des] fauteuils de la chambre du maréchal qui en raison de leur manque de fraîcheur (barré : état de vétusté) ne pourraient trouver leur place que dans un musée $\aleph^{37}$. On ignore si une restauration de ces éléments fut entreprise au lendemain de l'acquisition. Peu d'années après leur achat, en 1864, ils firent l'objet d'une publication dans la revue L'Art pour tous qui permet d'en connaître l'aspect à cette date ${ }^{38}$ (fig. 9). On notera en particulier que, à la différence de la disposition actuelle, l'alternance entre les lés de velours et ceux brodés est identique au niveau des pentes, des rideaux et des soubassements ; cet agencement est encore visible sur une photographie du lit publiée en $1929^{39}$. L'état actuel, qui ne respecte pas cet alignement, ne manquait pas de surprendre, et il est désormais possible de démontrer qu'il s'agit d'un remaniement postérieur. 
Figure 9

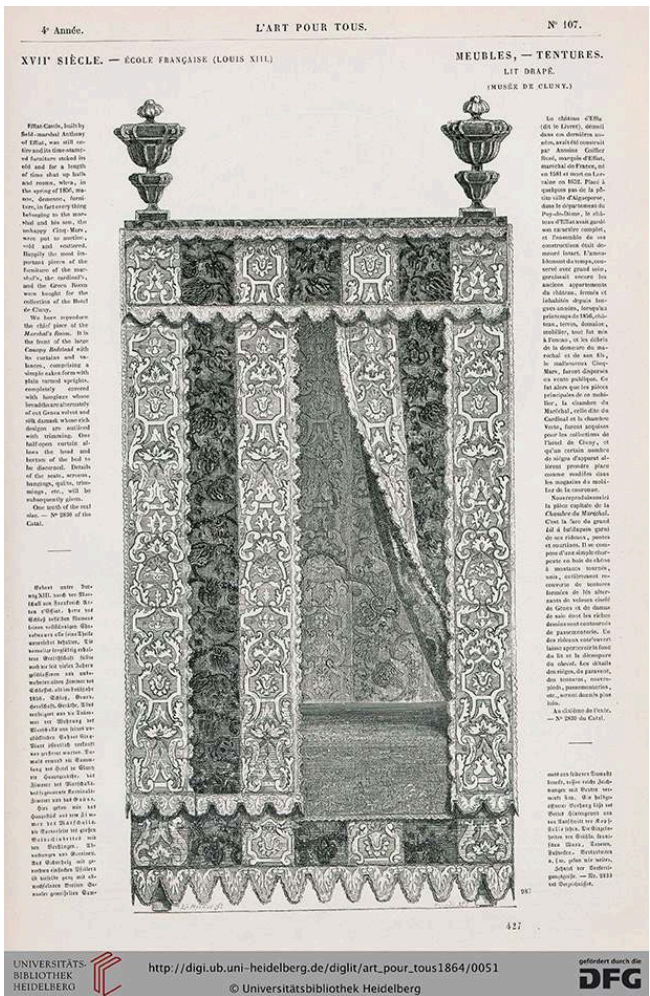

Gravure représentant le lit provenant du château d'Effiat publiée dans L'Art pour tous, $n^{\circ} 107,10$ avril 1864, p. 427.

(c) Universitätsbibliothek Heidelberg.

C'est à l'occasion de l'importante campagne de restauration du lit et des fauteuils entreprise au cours des années 1960 que cette modification paraît avoir été réalisée. La photographie du lit dans l'alcôve de la chambre du roi montre l'état de délabrement du lit dans les années 1950 (voir fig. 2), et les fauteuils étaient également dans un état comparable ${ }^{40}$; deux photographies de détail des broderies du lit permettent de mesurer la dégradation avancée du tissu ${ }^{41}$ (fig. 10). Pierre Verlet, conservateur en chef du département des Objets d'art au musée du Louvre, reconnaissait lui-même, dans un courrier daté de 1957, l'état « déplorable » du lit et celui « effroyable » des fauteuils, et ajoutait qu'il y aurait « lieu d'envisager un jour une coûteuse et délicate restauration de ces meubles $»^{42}$, opération qu'il « reculai[t] d'année en année depuis 1950, faute de crédits suffisants $»^{43}$. Celle-ci devait être menée par la maison Brocard à Paris quelques années plus tard, entre 1961 et 1966, certainement facilitée par le projet plus global de réaménagement muséographique des salles du département des Objets d'art alors en cours sous la direction de Pierre Verlet. 


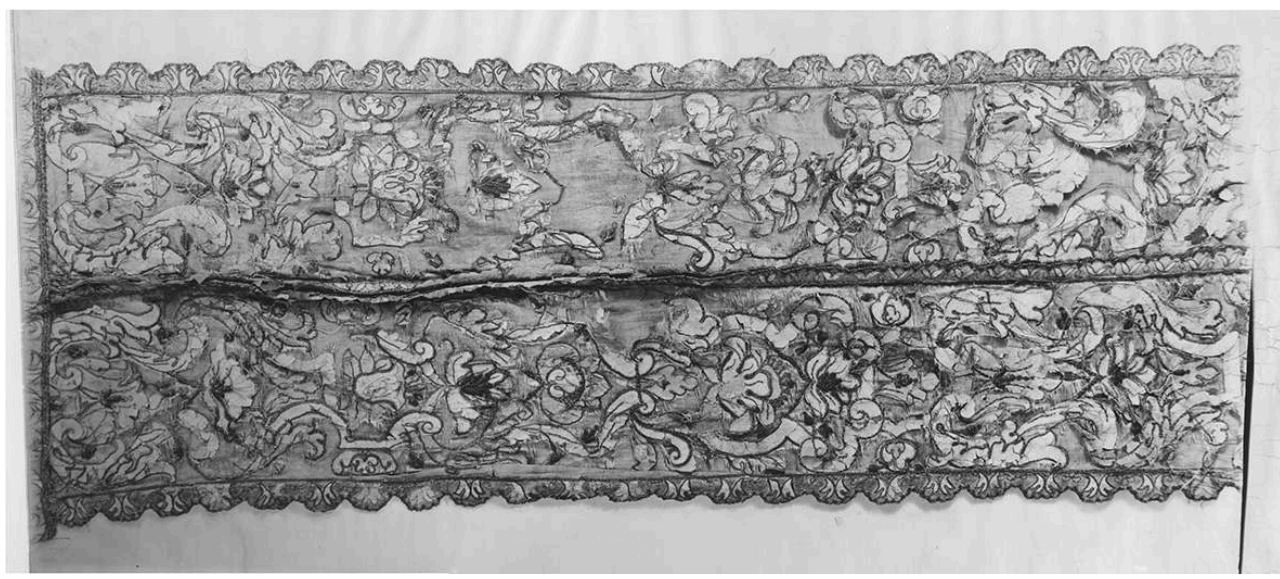

Lit provenant du château d'Effiat, détail d'un des rideaux avant la restauration des années 1960 .

(c) Documentation du département des Objets d'art.

En l'absence de rapport de restauration, seuls les devis, factures et quelques documents graphiques permettent de mesurer l'ampleur de l'intervention qui, suivant les pratiques de l'époque, a consisté à remplacer les parties les plus endommagées ${ }^{44}$. Pierre Verlet expliquait alors que « les fournitures de la maison Prelle [...] sont soit de velours, soit de satin, destinés à être découpés et incrustés dans les anciennes broderies, reprises à leur tour, le tout étant ensuite maquillé et unifié $»^{45}$, mais les métrages des livraisons de la maison Prelle - par exemple près de cinquante mètres de velours ciselé cramoisi pour le lit et les fauteuils - prouvent qu'il ne dût pas rester beaucoup de tissu ancien... Le coût de l'opération fut, on l'imagine, considérable et on notera que, déjà à cette époque, un tel investissement dans une restauration devait passer par les fourches caudines des financiers de l'administration. La lettre de Verlet qui vient d'être citée s'adressait au directeur des Musées de France afin de justifier auprès du contrôleur financier des dépenses réalisées et surtout à venir pour ce travail : « le total de la dépense n'était pas exactement prévisible ", il se justifie par la minutie du travail et les qualifications requises de la part des restaurateurs. Verlet ajoute: «Si le contrôleur veut bien venir soit au Louvre, soit à l'atelier Brocard, je lui montrerais ce qui est fait et ce que je souhaite voir être encore fait » et termine par un plaidoyer que l'on me permettra de reproduire ici car il pourrait servir de modèle aux conservateurs d'aujourd'hui : «La dépense peut paraître élevée. Mais il s'agit là d'un meuble de caractère irremplaçable, dont on ne trouverait guère l'équivalent que dans certains châteaux de Suède ou d'Angleterre. [...] Combien de dizaines de milliers de nouveaux francs coûterait (sic) les meubles d'Effiat si ils passaient en vente? Je ne peux le dire, faute d'exemple » et, citant le cas de l'acquisition de la table d'Æben, restaurée par les ateliers d'ébénisterie du Louvre, donc sans frais pour le Louvre, il conclut: "Nous n'avons pas d'atelier pour les tissus. On doit peut-être le déplorer ». Heureusement, Pierre Verlet pouvait jouer la carte politique en écrivant que lors «d'une première présentation pour l'ouverture des nouvelles salles du mobilier, Monsieur Malraux, inaugurant ces salles le $1^{\text {er }}$ août [1962], a spécialement admiré le travail de restauration accompli, nous assurant que nous pouvions le poursuivre", et semble ainsi avoir obtenu gain de cause, étant donné les sommes engagées dans les années suivantes pour terminer la restauration du lit et des fauteuils. 

documentation dont nous disposons, sur la partie textile du lit. Une autre opération de consolidation a été réalisée en 1993, de nouveau par la maison Brocard. Aucune information ne subsiste, en revanche, au sujet de la structure en bois. Elle semble pourtant avoir subi, elle aussi, des modifications drastiques, manifestement assez récemment (dans les années 1960 ?). L'analyse des parties supérieures des bois (quenouilles et ciel de lit) est rendue difficile par la présence des différents éléments textiles et il est délicat d'établir ce qui aurait été éventuellement changé, même si le système de tringles a visiblement été remanié. La couche a reçu, quant à elle, une armature destinée à remplacer le sommier et la matelasserie d'origine dont on ignore la disposition ancienne (fig. 11). On sait d'après les sources écrites et iconographiques contemporaines, comme les gravures d'Abraham Bosse déjà citées, que plusieurs matelas étaient superposés, formant une couche certainement plus haute que celle qui est maintenant restituée.

Figure 11

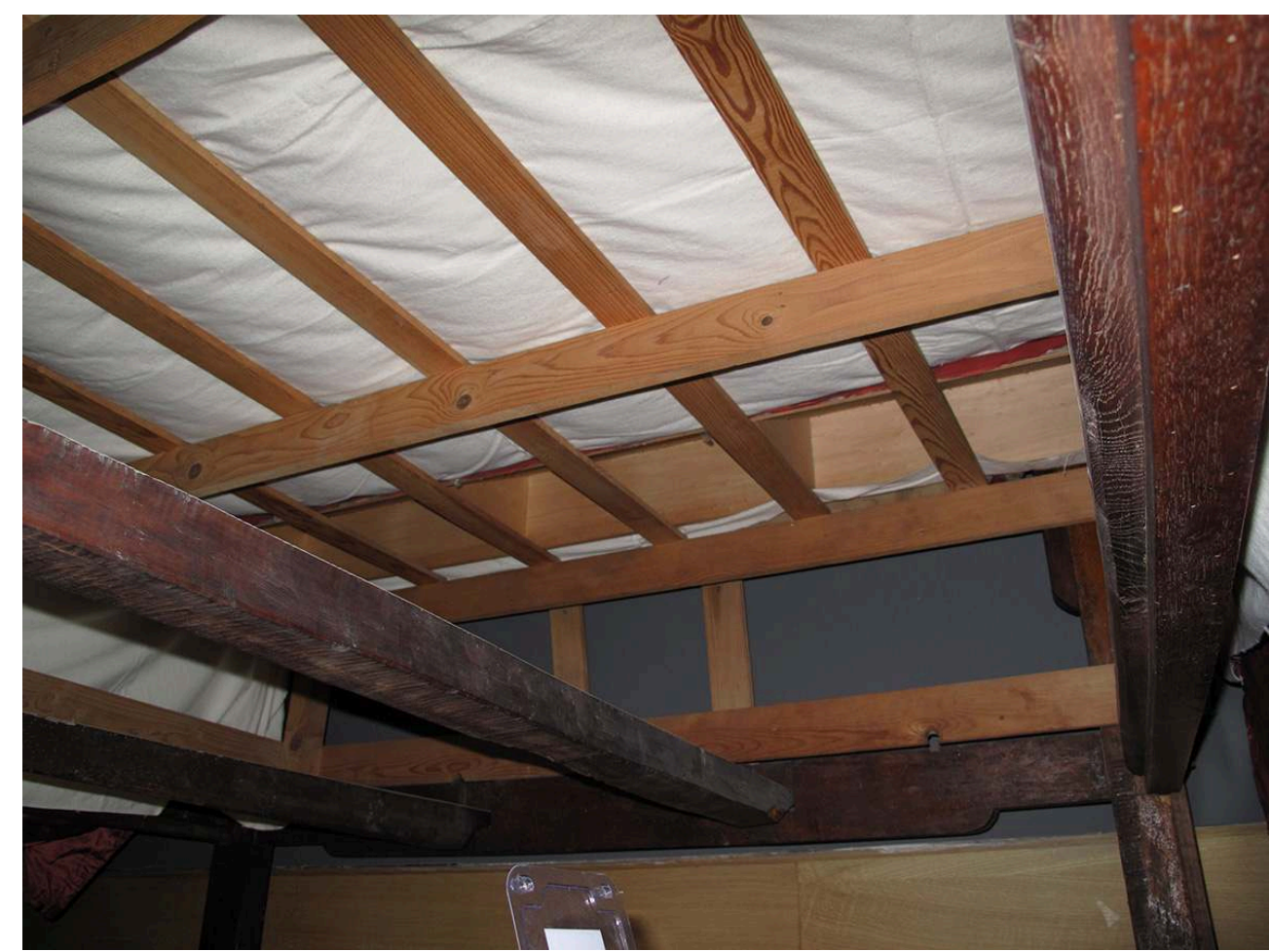

Lit provenant du château d'Effiat, vue de la structure faisant office de matelas. Musée du Louvre, département des Objets d'art.

(c) Anne Jacquin, 2009.

Le lit aujourd'hui visible dans le parcours des salles du département des Objets d'art a donc subi des modifications notables depuis qu'il a quitté le château d'Effiat. Il n'en constitue pas moins un témoignage exceptionnel et quasi unique dont l'importance artistique et historique a été comprise par Edmond Du Sommerard, permettant ainsi son entrée dans les collections publiques. Au-delà de cette pièce de mobilier, il serait certainement très intéressant d'étudier plus globalement l'ameublement du château d'Effiat à travers les trois générations des Ruzé, Antoine, Martin et son fils Antoine II († 1719). C'est à ce dernier que revient probablement la commande des deux autres lits 
achetés en 1856 par le musée de Cluny, dont l'un se trouve aujourd'hui au château d'Azay-le-Rideau et l'autre au musée national de la Renaissance au château d'Écouen. Comme le faisait remarquer le docteur Balme, une enquête dans les collections privées auvergnates permettrait certainement d'identifier d'autres objets provenant d'Effiat achetés au moment de la vente de $1856^{46}$.

\section{NOTES}

1. - BALME, Pierre. «Aux confins de l'Auvergne et du Bourbonnais, une demeure historique Effiat ». Auvergne littéraire et artistique, 1945, nº 114, p. 28.

2. - Paris, musée du Louvre, département des Objets d'art, dépôt du musée de Cluny, inv. Cl. 2550, noyer, sapin (sommier et chevet du lit), velours de soie ciselé, satin de soie, broderies d'application, fils métalliques, passementerie. H. $295 \mathrm{~cm}$; Long. $195 \mathrm{~cm}$; Larg. $165 \mathrm{~cm}$.

3. - CASTELLUCCIO, Stéphane. Le Style Louis XIII. Paris : Les Éditions de l'Amateur, 2002, p. 34 ; FERAY, Jean. Architecture intérieure et décoration en France des origines à 1875. Paris: BergerLevrault, 1997, p.119; PALLOT, Bill G.B. Le Mobilier du musée du Louvre. T. 2, Sièges et consoles (menuiserie) XVII et XVIII siècles. Dijon: Faton, 1993, p. 26-27; QUETTE, Anne-Marie. Le Mobilier français : Louis XIII, Louis XIV. Paris : Massin, 1996, p. 35.

4. - AUDIFFRED, Hyacinthe. Un mois à Vichy. Guide pittoresque et médical indispensable aux artistes et aux gens du monde. Paris/Lyon : Dawin et Fontaine/Giraudier, 1849, p. 133.

5. - Ces ventes eurent lieu en dépit d'une interdiction du tribunal civil de Riom (voir BEAUFRÈRE, Céline. L'Architecture du château d'Effiat. Mémoire de maîtrise sous la direction de J.-P. Bouillon, université de Clermont-Ferrand II, 1978, p. 87-88).

6. - «Séance du 19 avril ». Bulletin de la Société d'émulation du département de l'Allier, t. V, 1856, p. 220-221.

7. - Documentation du musée national du Moyen Âge, thermes et hôtel de Cluny.

8. - RUBELLES, Gontran de. "Quelques dires sur la terre et le château d'Effiat possédés par les comtes de Sampigny de 1726 à 1846 tirés de souvenirs de famille ». Bulletin de la Société d'histoire et d'archéologie de Vichy et des environs, juillet-septembre 1941, n 12, p. 315.

9. - Cette pièce se trouve encore en mains privées.

10. - Voir par exemple DU SOMMERARD, Edmond. Musée des Thermes et de l'Hôtel de Cluny. Catalogue et description des objets d'art [...] exposés au Musée. Paris : Hôtel de Cluny, 1863, p. 324 ; HARAUCOURT, Edmond. L'Histoire de la France expliquée au musée de Cluny. Guide annoté par salles et par séries. Paris : Librairie Larousse, 1922, p. 139 ; MARQUET de VASSELOT, Jean-Joseph. Musée de Cluny. Guide officiel. Paris : Imprimerie nationale/Musées nationaux, 1935, p. 89.

11. - Paris, musée du Louvre, département des Objets d'art, inv. OA 7825, en dépôt au musée du château de Blois (Loir-et-Cher) depuis 2006. Voir BOS, Agnès. "Mobilier Renaissance et néoRenaissance. Au sujet du lit Piot et des meubles du Louvre déposés au château de Blois ». Cahier du château et des musées de Blois, juin 2007-juin 2009, n 38-39, p. 55.

12. - Nous renvoyons aux travaux de recherche les plus récents sur le maréchal d'Effiat: MOTTE, Alice. « Antoine Ruzé d'Effiat (v. 1581-1632), surintendant des finances sous Louis XIII ». Positions des thèses de l'École nationale des chartes, 2009, voir le site : http://www.chartes.psl.eu/fr/positionsthese/antoine-ruze-effiat-v-1581-1632-surintendant-finances-louis-xiii [consulté le 19/11/2018] ; MOTTE, Alice. «Le maréchal d'Effiat (v. 1581-1632) : redécouverte d'une figure méconnue du 
ministériat de Richelieu ». Sparsae, $2^{\mathrm{e}}$ semestre 2015, 32 année, p. 15-24. Voir aussi : PARADIS, Olivier. «Effiat. Un château d'Auvergne dans l'histoire de France ». Sparsae, hors-série n 2, 2004. 13. - Contrairement à ce qui est souvent écrit, l'hôtel parisien du maréchal d'Effiat ne se trouvait pas dans le Marais, à l'angle des actuelles rues Vieille-du-Temple et du Trésor. La veuve du maréchal d'Effiat résidait encore en 1633 dans cet hôtel (Centre historique des Archives nationales, Y 173, fol. 463 ; Y 174, fol. 51), mais, en juillet 1634, elle achetait l'hôtel de la rue Vieille-du-Temple (voir BOYER, François. « La Mère de Cinq-Mars ». L'Auvergne historique, littéraire \& artistique, 1893-1894, $2^{\mathrm{e}}$ partie, p. 50, note 1). Dès cette date, elle y demeurait (Centre historique des Archives nationales, Y 175 , fol. $205 \mathrm{v}^{\circ}$ et 338 ) et elle y faisait réaliser des travaux (voir par exemple ibid., Minutier central des notaires parisiens, ET/XIX/411, 4 mars et 10 mars 1636), sous la direction de l'architecte Clément II Métezeau (LOIZEAU, Emmanuelle. «Clément II Métézeau, premier architecte du château d'Effiat ». Sparsae, $2^{\mathrm{e}}$ semestre $2015,32^{\mathrm{e}}$ année, p. 7).

14. - LOIZEAU, Emmanuelle. Art. cit., p. 5-14 ; Ead. « Le château de Chilly : questions d'attribution et de restitution ». Bulletin de la Société de l'histoire de l'art français, année 2013 (2014), p. 9-30.

15. - GADY, Alexandre. Jacques Lemercier, architecte et ingénieur du roi. Paris : Maison des Sciences de l'homme, 2005, p. 256-260. L'étude la plus détaillée sur les travaux du château reste le mémoire universitaire non publié de Céline Beaufrère (BEAUFRÈRE, Céline. Op. cit.).

16. - GADY, Alexandre. Op. cit., p. 260 et BEAUFRÈRE, Céline. Op. cit., p. 44-52.

17. - Paris, Arch. nat., MC/ET/XIX/404, 17 janvier 1633, inventaire après décès du maréchal d'Effiat. Je remercie Alice Motte pour ces renseignements.

18. - Les autres lits décrits dans l'inventaire ne peuvent, par ailleurs, pas correspondre au lit conservé au musée du Louvre du fait de leur couleur, du type de tissus qui les composent ou de leur forme.

19. - BASSOMPIERRE, François de. Mémoires du maréchal de Bassompierre contenans l'histoire de sa vie, et de ce qui s'est fait de plus remarquable à la Cour de France, pendant quelques années. Amsterdam : 1723, t. IV, p. 71.

20. - PARADIS, Olivier. "Richelieu à Effiat ». Sparsae, $n^{\circ} 60,2007$, p. 7-18. Dans le château de Denone, se trouve aujourd'hui un lit à colonnes, probablement un montage à partir d'éléments anciens, présenté comme le lit où aurait dormi le cardinal de Richelieu.

21. - Il serait « mort fou » selon un témoignage, certes peu digne de confiance (DURAND, Étienne. Méditations. Éd. Frédéric Lachèvre. Paris : Librairie Henri Leclerc, 1906, p. 251).

22. - Documents cités par BOYER, François. « La Mère de Cinq-Mars ». Art. cit., p. 60-62.

23. - ÉVERAT, Édouard. « Géraud de Champflour et les d'Effiat d'après les archives inédites de la famille de Champflour ». Mémoires de l'Académie des sciences, belles-lettres et arts de Clermont-Ferrand, 1928, p. 37-38.

24. - BEAUFRÈRE, Céline. Op. cit., p. 56, 70-71, 74.

25. - Les archives départementales du Puy-de-Dôme conservent un extrait de l'inventaire après décès de Martin Ruzé d'Effiat, dressé en juin 1645, dans le fonds des archives de la famille de Champflour (9 F 41), qui ne contient pas la liste des biens et meubles présents au château d'Effiat. 26. - Cet inventaire a été déjà étudié mais seulement pour les peintures, sculptures et tapisseries qui y sont décrites (FOURNIER, Pierre-François. « Euvres d'art du château d'Effiat ». Bulletin de la Société d'histoire et d'archéologie de Vichy et de ses environs, 1948, nº 34, p. 347-356).

27. - FURETIÈRE, Antoine. Dictionnaire universel, contenant généralement tous les mots françois tant vieux que modernes, et les termes de toutes les sciences et des arts. La Haye/Rotterdam: Arnout et Reinier Leers, 1690, vol. 1. Le dictionnaire de l'Académie française de 1694 décrit quant à lui la « couleur rouge pourprine » de ces fleurs.

28. - COURTIN, Nicolas. L'Art d'habiter à Paris au XVII siècle: l'ameublement des hôtels particuliers. Dijon : Faton, 2011, p. 207 et FURETIÈRE, Antoine. Op. cit., vol. 1.

29. - Constat d'état établi par Anne Jacquin, restauratrice de mobilier, en 2010. 
30. - Paris, musée du Louvre, département des Objets d'art, OA 246 a et b. Voir BOS, Agnès. Le Mobilier du Moyen Âge et de la Renaissance du musée du Louvre. Paris : Éditions du Louvre-Somogy, 2019, cat. 50, et aussi pour d'autres exemples, le catalogue de l'exposition Un temps d'exubérance. Les arts décoratifs sous Louis XIII et Anne d'Autriche. Cat. exp., Paris, Galeries nationales du Grand Palais, 9 avril-8 juillet 2002. Paris : Réunion des musées nationaux, 2002, cat. 134, p. 230-231.

31. - On notera que, lors de la vente de 1856 , des lots de tissus identiques à celui des deux autres lits subsistaient. Par ailleurs, j'avais eu l'opportunité d'examiner les fauteuils provenant d'Effiat avec le regretté Xavier Bonnet qui avait constaté que leur garniture présentait de nombreuses anomalies, et suggéré qu'il s'agissait de remaniements tardifs.

32. - BONNAFFÉ, Edmond. Le Meuble en France au XVI ${ }^{e}$ siècle. Paris/Londres: J. Rouam/Gilbert Wood, 1887, p. 212.

33. - Voir l'article de Nicolas Courtin dans ce volume sur la terminologie des lits au XVII ${ }^{\mathrm{e}}$ siècle.

34. - Voir par exemple, sur les sites, Le Cordonnier (http://parismuseescollections.paris.fr/fr/ musee-carnavalet/oeuvres/les-metiers-le-cordonnier\#infos-principales), La visite à l'accouchée (http://parismuseescollections.paris.fr/fr/musee-carnavalet/oeuvres/le-mariage-a-la-ville-lavisite-a-l-accouchee), La Femme qui bat son mari (http://parismuseescollections.paris.fr/fr/museecarnavalet/oeuvres/la-femme-qui-bat-son-mari) ou encore L'Hiver ( http:// parismuseescollections.paris.fr/fr/musee-carnavalet/oeuvres/l-hyver\#infos-principales) [consultés le 19/11/2018].

35. - Bibliothèque de l'Institut national d'histoire de l'art, collections Jacques Doucet, Fol. Est. 139, voir le site: http://bibliotheque-numerique.inha.fr/idurl/1/30728 [consulté le 19/11/2018].

36. - Grahal. Rapport d'intervention. Dépoussiérage du mobilier de la salle 32, département des Objets d'art, musée du Louvre, 2012.

37. - Dossier d'acquisition du lit et des fauteuils, conservé au centre de documentation du musée national du Moyen Âge, thermes et hôtel de Cluny.

38. - L'Art pour tous, $\mathrm{n}^{\circ} 107,10$ avril 1864, p. 427, $\mathrm{n}^{\circ} 109,30$ avril 1864, p. 435 et $\mathrm{n}^{\circ}$ 110, 10 mai 1864, p. 440. Certaines gravures publiées alors ont été réutilisées dans la revue américaine The Art amateur, mars 1884, vol. 10, $\mathrm{n}^{\circ} 4$, p. 92-93 et celle du lit est reprise par Henry HAVARD dans son Dictionnaire de l'ameublement et de la décoration. Paris : Maison Quantin, 1894, t. I, col. 1080.

39. - HENRIOT, Gabriel. Le Meuble depuis l'Antiquité jusqu'au milieu du XIXe siècle. Paris : Librairie des Arts décoratifs/A. Calavas, 1929, p. 188.

40. - Les fauteuils étaient en mauvais état depuis les années 1920 au moins, ainsi qu'on peut le voir sur une photographie montrant l'un des fauteuils, publiée par Henri-Marcel MAGNE dans L'Art appliqué aux métiers. Paris : H. Laurens éditeur, 1922-1928, T. VIII, Décor du mobilier. Meubles et sièges. 1928, p.151, voir le site: https:/gallica.bnf.fr/ark:/12148/bpt6k64930952/ f165.item.r=effiat.

41. - Musée du Louvre, documentation du département des Objets d'art.

42. - Pierrefitte-sur-Seine, Centre des Archives nationales, 20144787/4, fonds des archives des Musées nationaux, ancienne sous-série M4, 1957.

43. - Ibid., 20150337/390, fonds des archives des Musées nationaux, ancienne cote 9 LL 35, lettre du 6 novembre 1962.

44. - Ibid., dossiers des années 1961 à 1966, et 201447887/27, ancienne sous-série M16.

45. - Ibid., 20150337/390, fonds des archives des Musées nationaux, ancienne cote 9 LL 35, lettre du 6 novembre 1962.

46. - BALME, Pierre. Art. cit., p. 29. 


\section{RÉSUMÉS}

Le lit provenant du château d'Effiat (Puy-de-Dôme) et aujourd'hui présenté dans les salles du département des Objets d'art du musée du Louvre est connu pour être l'un des rares exemplaires survivants des lits «à la française » du XVII ${ }^{\mathrm{e}}$ siècle. Il est exceptionnel par la richesse des textiles qui le forment, une alternance de lés de velours de soie ciselé avec des lés ornés de broderies d'application. Acheté par le musée de Cluny au moment de la vente d'une partie du mobilier du château d'Effiat en 1856, avant d'être déposé au musée du Louvre après la Seconde Guerre mondiale, le lit a toujours été considéré comme celui du maréchal d'Effiat (v. 1581-1632), puissant ministre de Louis XIII et proche du cardinal de Richelieu, pour le château familial qu'il avait largement contribué à reconstruire. Or aucun des lits décrits dans son inventaire après décès ne semble correspondre au lit du Louvre, alors qu'il est possible de rapprocher ce dernier de la description du lit de Martin Ruzé d'Effiat (1612-1644), fils du maréchal d'Effiat, ce qui conduit à émettre l'hypothèse que le lit a été réalisé pour celui-ci. Dès son entrée dans les collections publiques, le lit était en mauvais état, la garniture textile étant particulièrement fragile. Au cours des années 1960, une opération de restauration majeure du lit et des fauteuils qui l'accompagnent a été menée par la maison Brocard, mais l'examen du lit montre qu'il avait fait l'objet d'autres remaniements, notamment au niveau de la structure en bois.

The bed which originally came from the Effiat chateau in the Puy-de-Dôme department and which is presented today in the Louvre, in the rooms of the department devoted to art objects, is well known as one of the rare surviving examples of a 'French-style' bed of the seventeenth century. It is remarkable for the richness of the textiles it comprises, made up of strips of embossed silk velvet, alternating with strips decorated with embroidery applications. The bed was acquired by the Cluny museum in 1856 when a part of the furniture of the Effiat chateau was auctioned off. It was transferred to the Louvre after the Second World War. It was always thought to be the bed of the Marshall d'Effiat (1581-1632), an influential minister of Louis XIII, closely associated with the Cardinal de Richelieu, whose family chateau he had helped rebuild. However, none of the beds described in his inventory after death seem to correspond with the bed at the Louvre today, whilst it is possible to see correspondences with the description of a bed belonging to Martin Ruzé d'Effiat (1612-1644), the Marshall's son. The hypothesis today is that the bed was made for this son. When it entered the public museum collections, the bed was in a sorry state of conservation and its textile trimmings were particularly fragile. During the 1960s, a major restoration campaign was undertaken by the Brocard firm on the bed and on some armchairs, but a close examination of the bed shows that it had already seen earlier changes, notably to its wooden structure.

\section{INDEX}

Keywords : furniture, bed, textile, embroidery, Louvre museum, Cluny Museum, Effiat (chateau), Antoine Ruzé d'Effiat, Maréchal d'Effiat, Martin Ruzé d'Effiat, Pierre Verlet, Maison Brocard (Paris)

Mots-clés : mobilier, lit, textile, broderie, musée du Louvre, musée de Cluny, Effiat (château), Antoine Ruzé d'Effiat, maréchal d'Effiat, Martin Ruzé d'Effiat, Pierre Verlet, Maison Brocard (Paris) 
AUTEUR

AGNĖS BOS

Lecturer, School of Art History, University of St Andrews ab421@st-andrews.ac.uk 